\title{
Advanced nonlinear control of three phase series active power filter
}

\author{
Y. Abouelmahjoub ${ }^{1}$, A. Abouloifa ${ }^{2}$, F. Giri ${ }^{3}$, F.Z. Chaoui ${ }^{1}$ and M. Kissaoui ${ }^{1}$ \\ ${ }^{1}$ RCSLNL/LM2PI Lab, Mohammed V University Souissi, Rabat, Morocco \\ ${ }^{2}$ L.T.I Lab, FSBM, University HASSAN II Casablanca, Morocco \\ ${ }^{3}$ GREYC Lab, University of Caen Basse-Normandie, Caen, France
}

\begin{abstract}
The problem of controlling three-phase series active power filter (TPSAPF) is addressed in this paper in presence of the perturbations in the voltages of the electrical supply network. The control objective of the TPSAPF is twofold: (i) compensation of all voltage perturbations (voltage harmonics, voltage unbalance and voltage sags), (ii) regulation of the DC bus voltage of the inverter. A controller formed by two nonlinear regulators is designed, using the Backstepping technique, to provide the above compensation. The regulation of the DC bus voltage of the inverter is ensured by the use of a diode bridge rectifier which its output is in parallel with the DC bus capacitor. The Analysis of controller performances is illustrated by numerical simulation in Matlab/Simulink environment.
\end{abstract}

\section{Introduction}

The harmonic contamination is a harmful problem in Electric Power System. Indeed, the increasing use of rectifiers, thyristor power converters, UPS (Uninterruptible Power Supply), switching power supplies and other nonlinear loads are known to cause serious problems in electric power systems. These devices are responsible for the contamination of the line currents with the harmonics of various orders. The harmonics of the current circulating through the line impedance produce distortion in the voltages of power system. Indeed, the distortion, the unbalance and sags of the power system voltages cause several power quality problems, including the incorrect operation of some sensitive loads [1]. The TPSAPF's are an appropriate solution to protect the sensitive load against voltage perturbations.

In most papers, the researchers often use, for the control of the TPSAPF, the method of the instantaneous power [2]. In this paper, the work focuses on the advanced nonlinear control of three-phase series active power filter in the presence of disturbances in the power system voltages by using a method based on the calculation of the references of the series voltages. A controller that is formed by two nonlinear regulators is designed, using the Backstepping technique, to ensure compensation of voltage perturbations (voltage harmonics, voltage unbalances and voltage sags) at the terminals of the sensitive loads. The regulation of DC bus voltage of the inverter is provided by the use of a diode bridge rectifier which its output is connected in parallel with the DC bus capacitor. This theoretical result is confirmed by numerical simulation.

The paper is organized as follows: the system includes the electric network and the DC/AC converter is modeled in Section 2, the control problem is formulated in Section 3 which also includes the design. Performances of controller are illustrated by simulation in Section 4. A general conclusion ends the paper.

\section{Series active power filter}

\subsection{Series active power filter topology}

Three-phase series active power filter under study has the structure of figure 1 . In the AC side, the TPSAPF is inserted between the perturbed voltage source and a sensitive load, a second $\operatorname{order}\left(R_{f}, L_{f}, C_{f}\right)$ passive output filter used to connect the inverter to grid through voltages injected by three current transformers. In the DC side it has a capacitor of energy storage $C_{d c}$. The circuit operates according to the well known Pulse Width Modulation principle (PWM) [3,4,5]. The switching function ${ }_{i}$ of the inverter is defined by:

$$
{ }_{i}=\left\{\begin{array}{cccc}
+1 & \text { if } & S_{i} & \text { is } O N \text { and } S_{i+3} \text { is OFF } \\
1 & \text { if } & S_{i} & \text { is OFF and } S_{i+3} \text { is ON }
\end{array} \quad(\text { for } i=1,2,3)\right.
$$




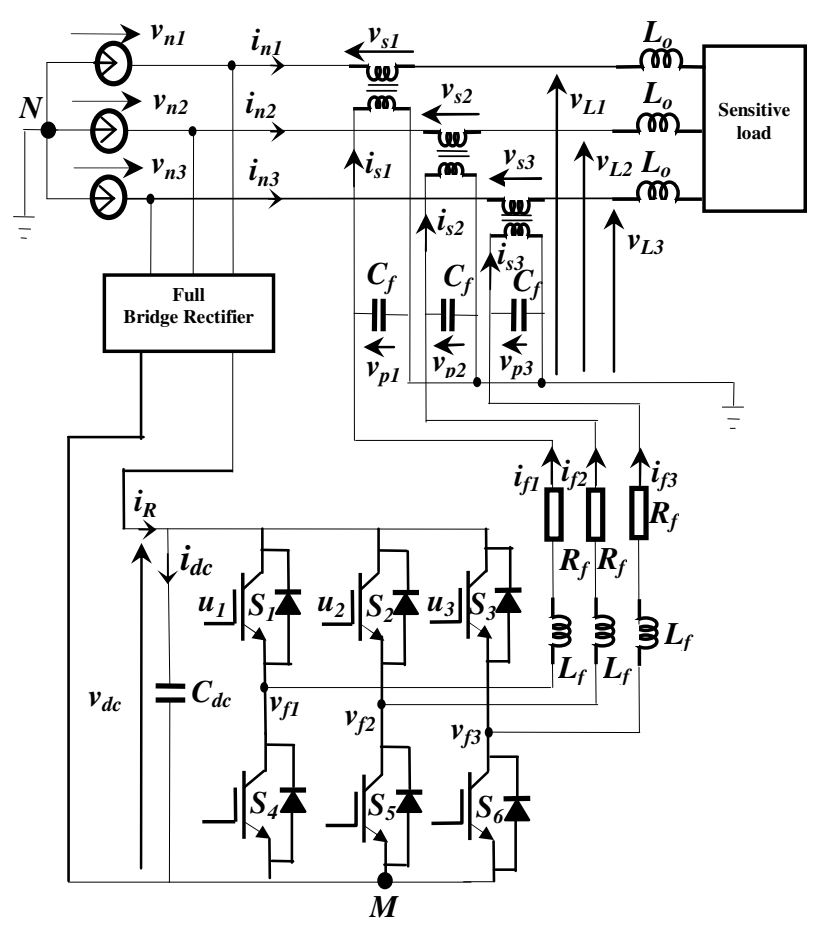

Fig. 1. Three- phase series active power filter.

\subsection{Series active power filter modeling}

The average model of the TPSAPF in dq frame is the following:

$\frac{d}{d t}\left(\begin{array}{l}x_{s d} \\ x_{s q}\end{array}\right)=\left(\begin{array}{cc}0 & \\ & 0\end{array}\right)\left(\begin{array}{l}x_{s d} \\ x_{s q}\end{array}\right)+\frac{m_{s}}{C_{f}}\left(\begin{array}{c}x_{f d} \\ x_{f q}\end{array}\right)+\frac{m_{s}^{2}}{C_{f}}\left(\begin{array}{l}i_{n d} \\ i_{n q}\end{array}\right)$

$\frac{d}{d t}\left(\begin{array}{l}x_{f d} \\ x_{f q}\end{array}\right)=\left(\begin{array}{cc}\boldsymbol{R}_{f} / \boldsymbol{L}_{f} & \\ & \boldsymbol{R}_{f} / \boldsymbol{L}_{f}\end{array}\right)\left(\begin{array}{l}x_{f d} \\ x_{f q}\end{array}\right)+\frac{x_{d c}}{2 \boldsymbol{L}_{f}}\left(\begin{array}{ll}1 & 0 \\ 0 & 1\end{array}\right)\left(\begin{array}{l}u_{d} \\ u_{q}\end{array}\right) \frac{1}{\boldsymbol{m}_{s} \boldsymbol{L}_{f}}\left(\begin{array}{l}\boldsymbol{x}_{\mathrm{s} d} \\ \boldsymbol{x}_{s q}\end{array}\right)(1 \mathrm{~b})$

$\frac{d x_{d c}}{d t}=\frac{1}{C_{d c}}\left(i_{R} \quad \frac{1}{2}\left(u_{d} x_{f d}+u_{q} x_{f q}\right)\right)$

where $x_{s d}, x_{s q}, x_{f d}, x_{f q}, x_{d c}, u_{d}$ and $u_{q}$ respectively denote the average values over cutting periods of the signals $v_{s d}, v_{s q}, i_{f d}, i_{f q}, v_{d c},{ }_{d}$ and ${ }_{q} . m_{s}$ is the transformation ratio of current transformers

\section{Controller design}

The controller synthesis is carried out by two stages. First, a voltage loop is designed to compensate all voltage perturbations. Second, a diode bridge rectifier is used to ensure the regulation of DC bus voltage.

\subsection{Voltages series loop design}

In order to compensate the voltage disturbances in the power system, the voltages $v_{s 1}, v_{s 2}$ and $v_{s 3}$ injected by three-phase series active power filter should respectively follow their references $v_{s 1}^{*}, v_{s 2}^{*}$ and $v_{s 3}^{*}$ which are defined by:

$$
\left[v_{s 123}\right] \quad\left[v_{s 123}\right]^{*}=\left[v_{n 123}\right]\left[v_{L 123}\right]^{*}
$$

where the voltages $v_{L 1}, v_{L 2}$ and $v_{L 3}$ at the terminals of the load must be sinusoidal and form a balanced threephase system. Expressing the references voltages from equation (2) in the dq frame, it comes:

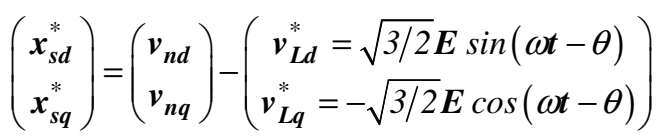

To force the voltages $x_{s d}$ and $x_{s q}$ in order to respectively follow the references $x_{s d}^{*}$ and $x_{s q}^{*}$, a controller formed by two nonlinear regulators, using the Backstepping technique [6], is proposed in the follow:

Step 1 Stabilization of the subsystem $e_{1}=\left(\begin{array}{l}e_{1 d} \\ e_{1 q}\end{array}\right)$

Let's introduce the tracking error $e_{1}$

$e_{l}=\left(\begin{array}{l}e_{I d} \\ e_{l q}\end{array}\right)=\left(\begin{array}{ll}x_{s d} & x_{s d}^{*} \\ x_{s q} & x_{s q}^{*}\end{array}\right)$

Given (1a), the time derivative of error $e_{1}$ is:

$\left(\begin{array}{c}\dot{\boldsymbol{e}}_{l d} \\ \dot{\boldsymbol{e}}_{l q}\end{array}\right)=\left(\begin{array}{cc}\boldsymbol{x}_{s q}+\left(\boldsymbol{m}_{s} \boldsymbol{x}_{f d}\right) / \boldsymbol{C}_{f}+\left(\boldsymbol{m}_{s}^{2} \boldsymbol{i}_{n d}\right) / \boldsymbol{C}_{f} & \dot{\boldsymbol{x}}_{s d}^{*} \\ \boldsymbol{x}_{s d}+\left(\boldsymbol{m}_{s} \boldsymbol{x}_{f q}\right) / \boldsymbol{C}_{f}+\left(\boldsymbol{m}_{s}^{2} \boldsymbol{i}_{n q}\right) / \boldsymbol{C}_{f} & \dot{\boldsymbol{x}}_{s q}^{*}\end{array}\right)$

Introduce the candidate Lyapunov function

$V_{l}=\frac{1}{2} e_{1}^{T} e_{l}=\frac{1}{2}\left(e_{l d}^{2}+e_{1 q}^{2}\right)$

Its dynamic is given by:

$\dot{V}_{l}=\dot{e}_{l d} e_{1 d}+\dot{e}_{1 q} e_{1 q}$

The choice $\dot{V}_{l}=c_{l d} e_{1 d}^{2} \quad c_{1 q} e_{l q}^{2} \quad$ ensuring the asymptotic stability of (5) with respect to the Lyapunov function (6) where $c_{l d} \succ 0$ and $c_{l q} \succ 0$ are a design parameters. Indeed, this choice would imply:

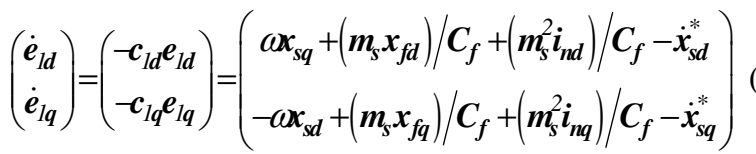

If we consider that $m_{s} x_{f d} / C_{f}$ and $m_{s} x_{f q} / C_{f}$ are, respectively, the actual commands in the preceding equation (8), then the error $e_{1}=\left(\begin{array}{l}e_{1 d} \\ e_{1 q}\end{array}\right)$ will be regulated to zero if: 
$\left(\begin{array}{l}\boldsymbol{m}_{s} x_{f d} / C_{f} \\ m_{s} x_{f q} / C_{f}\end{array}\right)=\left(\begin{array}{c}d \\ q\end{array}\right)$

where $\left(\begin{array}{l}d \\ q\end{array}\right)$ are the stabilizing functions defined by:

$\left(\begin{array}{c}d \\ q\end{array}\right)=\left(\begin{array}{ccc}c_{l d} e_{l d} & x_{s q} & \left(m_{s}^{2} i_{n d}\right) / C_{f}+\dot{x}_{s d}^{*} \\ c_{l q} e_{l q}+ & x_{s d} & \left(m_{s}^{2} i_{n q}\right) / C_{f}+\dot{x}_{s q}^{*}\end{array}\right)$

As $m_{s} x_{f d} / C_{f}$ and $m_{s} x_{f q} / C_{f}$ are not the actual controls, then new variable error $e_{2}=\left(\begin{array}{c}e_{2 d} \\ e_{2 q}\end{array}\right)$ between the virtual controls and their desired values $\left(\begin{array}{l}d \\ q\end{array}\right)$ are defined as follow:

$e_{2}=\left(\begin{array}{l}e_{2 d} \\ e_{2 q}\end{array}\right)=\left(\begin{array}{ll}m_{s} x_{f d} / C_{f} & d \\ m_{s} x_{f q} / C_{f} & q\end{array}\right)$

Then, by using (10) and (11), equation (5) becomes:

$\left(\begin{array}{l}\dot{\boldsymbol{e}}_{1 d} \\ \dot{\boldsymbol{e}}_{1 \boldsymbol{q}}\end{array}\right)=\left(\begin{array}{c}\boldsymbol{c}_{1 d} \boldsymbol{e}_{1 d}+\boldsymbol{e}_{2 d} \\ \boldsymbol{c}_{1 q} \boldsymbol{e}_{1 q}+\boldsymbol{e}_{2 q}\end{array}\right)$

Thereafter, the derivative of equation (6) becomes:

$\dot{V}_{1}=c_{1 d} e_{1 d}^{2} \quad c_{1 q} e_{1 q}^{2}+e_{1 d} e_{2 d}+e_{1 q} e_{2 q}$

end of step 1 .

Step 2 Stabilization of the subsystem $\left(e_{1}, e_{2}\right)$

To achieve the above objective, the controller forcing the errors $\left(e_{1}, e_{2}\right)$ to tend to zero, one needs the dynamics of $e_{2}=\left(\begin{array}{l}e_{2 d} \\ e_{2 q}\end{array}\right)$. We derive (11), using (1b) we obtain:

$\left(\begin{array}{l}\dot{e}_{2 d} \\ \dot{e}_{2 q}\end{array}\right)=\left(\begin{array}{llll}\frac{m_{s} R_{f}}{C_{f} L_{f}} x_{f d}+\frac{m_{s}}{C_{f}} x_{f q}+\frac{m_{s} x_{d c}}{2 C_{f} L_{f}} u_{d} & \frac{1}{C_{f} L_{f}} x_{s d} & { }_{d} \\ \frac{m_{s}}{C_{f}} x_{f d} & \frac{m_{s} R_{f}}{C_{f} L_{f}} x_{f q}+\frac{m_{s} x_{d c}}{2 C_{f} L_{f}} u_{q} & \frac{1}{C_{f} L_{f}} x_{s q} & \cdot\end{array}\right)$

Introduce the candidate Lyapunov function

$V_{2}=V_{1}+\frac{1}{2} e_{2}^{T} e_{2}$

The derivative of (15) is obtained by using (13):

$\dot{V}_{2}=c_{1 d} e_{1 d}^{2} \quad c_{1 q} e_{l q}^{2}+e_{2 d}\left(e_{1 d}+\dot{e}_{2 d}\right)+e_{2 q}\left(e_{1 q}+\dot{e}_{2 q}\right)$

To ensure the negativity of $\dot{V}_{2}$, it is necessary that: $\left(\begin{array}{c}\dot{e}_{2 d} \\ \dot{e}_{2 q}\end{array}\right)=\left(\begin{array}{cc}\boldsymbol{e}_{1 d} & \boldsymbol{c}_{2 d} \boldsymbol{e}_{2 d} \\ \boldsymbol{e}_{1 \boldsymbol{q}} & \boldsymbol{c}_{2 q} \boldsymbol{e}_{2 q}\end{array}\right)$

where $c_{2 d} \succ 0$ and $c_{2 q} \succ 0$ are a design parameters then,

From the equations (14) and (17) we deduce the expressions of the laws of actual control in the dq reference

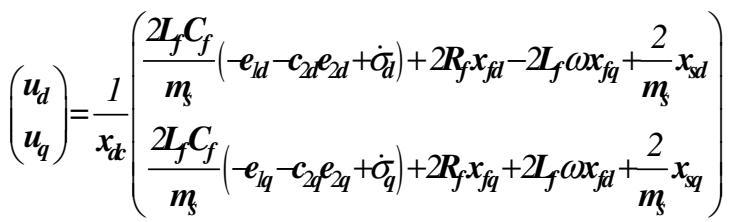

\subsection{Voltage of DC bus loop design}

The regulation of the DC bus voltage is provided by the use of a full bridge rectifier which its output is connected in parallel with the capacitor of the DC bus. The voltage $v_{d c}$ of the DC bus is regulated to the average value of the output voltage of the rectifier bridge: $U_{\text {moy }}=3 \sqrt{3} \mathrm{E} /$.

\section{Numerical simulations}

In order to simulate the behavior of the three-phase series active power filter shown in figure 1, the chosen nonlinear load is a three-phase bridge rectifier which supplies an inductive load comprising a resistor $R_{L}$ and an inductor $L_{L}$. The coil $L_{o}$ is inserted to the input of three-phase bridge rectifier to limit the $d i_{n k} / d t \quad k \quad\{1,2,3\}$.

The performances of the proposed controller are now numerically evaluated with the following characteristics:

Table 1. Parameters simulation values

\begin{tabular}{|c|c|c|}
\hline Parameters & Symbol & Value \\
\hline Network & $E, f$ & $220 \sqrt{2} \mathrm{~V}, 50 \mathrm{~Hz}$ \\
\hline DC bus & $C_{d c}$ & $9000 \mathrm{~F}$ \\
\hline TPSAPF & $R_{f}, L_{f}, C_{f}$ & $80 m, 3 m H, 1200 \quad \mathrm{~F}$ \\
\hline Rectifier & $R_{L}, L_{L}, L_{o}$ & $20,500 m \mathrm{H}, 5 \mathrm{mH}$ \\
\hline $\begin{array}{c}\text { Voltages } \\
\text { regulators }\end{array}$ & $c_{1 d}=c_{2 d}$ & $3000 \mathrm{~s}^{1}$ \\
$c_{1 q}=c_{2 q}$ & $6000 \mathrm{~s}^{1}$ \\
\hline
\end{tabular}

\subsection{Voltage harmonics compensation}

The three-phase source voltages are balanced but contain the $5^{\text {th }}$ and $7^{\text {th }}$ harmonic components. Their expressions are given by:

$$
\begin{aligned}
& v_{n l}(t)=E_{1} \operatorname{Sin}\left({ }_{n} t\right) \quad E_{5} \operatorname{Sin}\left({ }_{5}{ }_{n} t\right)+E_{7} \operatorname{Sin}\left({ }{ }_{n} t\right) \\
& v_{n 2}(t)=E_{1} \operatorname{Sin}\left({ }_{n} t \frac{2}{3}\right) \quad E_{5} \operatorname{Sin}\left({ }_{5}{ }_{n} t+\frac{2}{3}\right) \\
& +E_{7} \operatorname{Sin}\left(\begin{array}{lll}
7 & & \\
& t & \frac{2}{3}
\end{array}\right)
\end{aligned}
$$




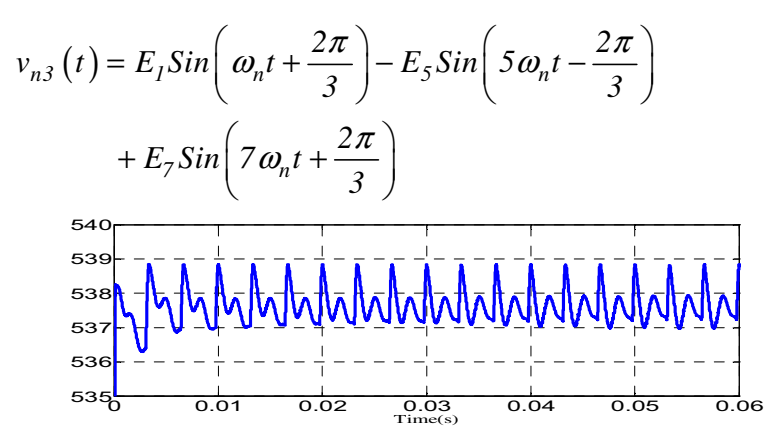

Fig. 2. Voltage of DC bus $v_{d c}$.

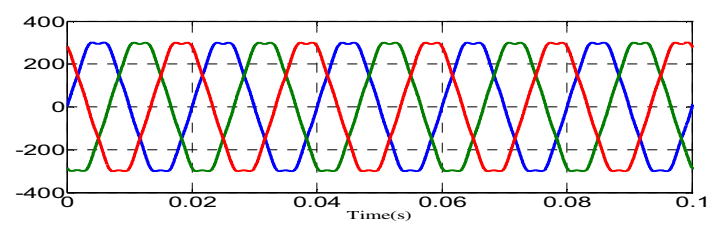

Fig. 3. Source voltages harmonics $\left(v_{n 1} v_{n 2} v_{n 3}\right)$.

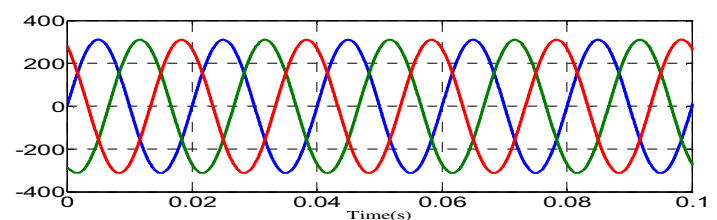

Fig. 4. Load voltages $\left(v_{L 1} v_{L 2} v_{L 3}\right)$ after compensation.

\subsection{Voltage unbalance compensation}

The three-phase source voltages are unbalanced, but do not contain harmonic components. Their expressions are given by:

$$
\begin{aligned}
& v_{n l}(t)=E_{l} \operatorname{Sin}\left({ }_{n} t\right)+0.1 E_{1} \operatorname{Sin}\left({ }_{n} t\right) \\
& v_{n 2}(t)=E_{1} \operatorname{Sin}\left({ }_{n} t \frac{2}{3}\right)+0.1 E_{1} \operatorname{Sin}\left({ }_{n} t+\frac{2}{3}\right) \\
& v_{n 3}(t)=E_{1} \operatorname{Sin}\left({ }_{n} t+\frac{2}{3}\right) \quad 0.1 E_{1} \operatorname{Sin}\left({ }_{n} t \quad \frac{2}{3}\right)
\end{aligned}
$$

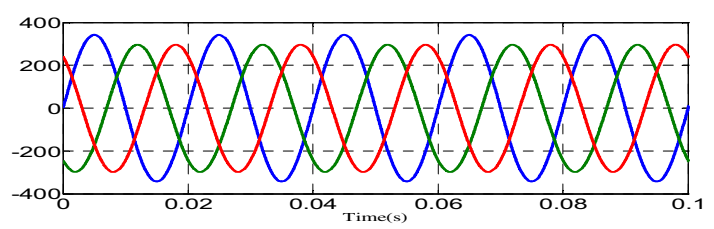

Fig. 5. Source voltages unbalanced $\left(\begin{array}{llll}v_{n 1} & v_{n 2} & v_{n 3}\end{array}\right)$.

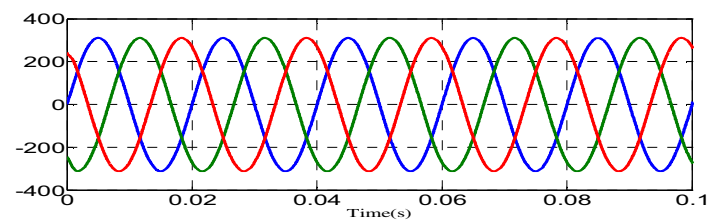

Fig. 6. Load voltages $\left(\begin{array}{llll}v_{L 1} & v_{L 2} & v_{L 3}\end{array}\right)$ after compensation.

\subsection{Voltage sags compensation}

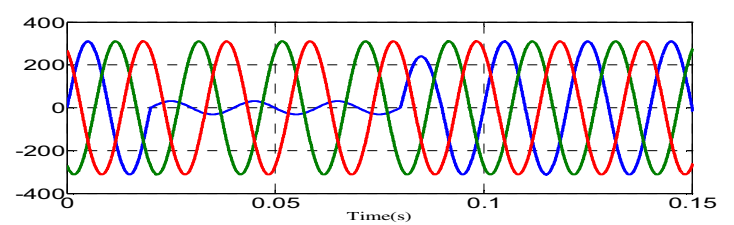

Fig. 7. Source voltages sags $\left(v_{n 1} v_{n 2} v_{n 3}\right)$.

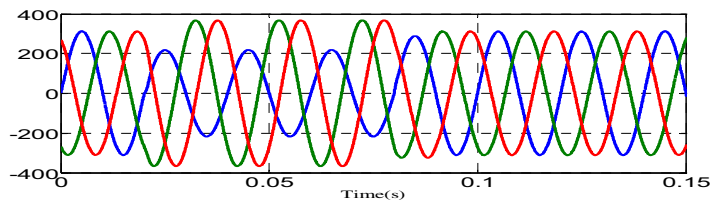

Fig. 8. Load voltages $\left(v_{L 1} v_{L 2} v_{L 3}\right)$ after compensation.

The performances of the controller are illustrated by figures 2 to 8 . The figure 2 shows the voltage of DC bus $v_{d c}$ converges, in the mean to the average value of the output voltage of the rectifier bridge: $U_{\text {moy }}=3 \sqrt{3} E /$. Figure 3 shows the distortion in source voltages $\left(v_{n 1} v_{n 2} v_{n 3}\right)$. Figure 4 clearly shows that the load voltages $\left(v_{L 1} v_{L 2} v_{L 3}\right)$ after compensation are balanced and sinusoidal. Figure 5 shows source voltages unbalanced $\left(v_{n 1} v_{n 2} v_{n 3}\right)$. Figure 6 shows that the load voltages $\left(v_{L 1} v_{L 2} v_{L 3}\right)$ after compensation are balanced and sinusoidal. Figure 7 shows the sags in source voltages $\left(v_{n 1} v_{n 2} v_{n 3}\right)$. Figure 8 shows that the load voltages $\left(\begin{array}{llll}v_{L 1} & v_{L 2} & v_{L 3}\end{array}\right)$ after compensation are balanced and sinusoidal after the voltages sags.

\section{Conclusion}

The problem of controlling three-phase series active power filter is addressed in this paper. The control objective is to compensate all voltage perturbations (voltage harmonics, voltage unbalance and voltage sags) caused by nonlinear loads. Indeed the harmonics of the current generated by the nonlinear load, cause voltage distortion of the power source. The solution of the problem is processed using a controller formed by two nonlinear regulators by using the Backstepping technique to compensate the voltages perturbations. The simulation results show that it performs perfectly the objectives.

\section{References}

[1] J. G. Pinto, H. Carneiro, B. Exposto, C. Couto, J. L. Afonso, Transformerless Series Active Power Filter to Compensate Voltage Disturbances, Proceedings of the 14th European Conference on Power Electronics and Applications. Birmingham, United Kingdom, Aug. 30 Sept (2011).

[2] S.W. Han, S.Y. Lee, G. H. Choe, A 3-Phase Series active Power Filter with Compensate Voltage Drop and voltage Unbalance . ISIE , 2001. 1032-1037.

[3] P.T. Krein, J. Bentsman, R.M. Bass, B. Lesieutre. On the use of averaging for analysis of power electronic system, IEEE Trans Power Electronics 5 ,1990,182-190.

[4] C.K.Tse, M.H.L. Chow, Theoretical study of switching converters with power factor correction and output regulation, IEEE Trans Circuits Syst. 47, 2000, 1047-55.

[5] R. Erickson, M. Madigan, S. Singer, Design of simple high power factor rectifier based on the flyback converter, IEEE Applied Power Electronics Conference and Exposition, Los Angeles, CA, USA, 1990, $792-801$.

[6] A. Abouloifa, F. Giri, I. Lachkar, and F.Z. Chaoui, Formal Framework for Nonlinear control of PWM AC/DC Boost Rectifiers Controller Design and Average Performance Analysis, IEEE Trans. Contr. Syst. Tech. 18, 2010, 323335. 